\title{
Intubation-Surfactant: Extubation on Continuous Positive Pressure Ventilation. Who Are the Best Candidates?
}

\author{
Maria Livia Ognean ${ }^{*}$, Silvia-Maria Stoicescu², Oana Boantăํㅜ, Leonard Năstase², \\ Carmen Gliga 3 , Manuela Cucerea3,4 \\ ${ }^{1}$ Clinical County Emergency Hospital Sibiu, Neonatology Department \\ 2 University of Medicine and Pharmacy Carol Davila Bucuresti, Institute of Mother and Child Care- Polizu, \\ Neonatology Department \\ 3 Clinical County Emergency Hospital Târgu Mureș, Regional Neonatal Intensive Care Center \\ 4 University of Medicine and Pharmacy Târgu Mureș
}

\begin{abstract}
Introduction: Respiratory distress syndrome (RDS) continues to be the leading cause of illness and death in preterm infants. Studies indicate that INSURE strategy (INtubate-SURfactant administration and Extubate to nasal continuous positive airway pressure [nCPAP]) is better than mechanical ventilation (MV) with rescue surfactant, for the management of respiratory distress syndrome (RDS) in very low birth weight (VLBW) neonates, as it has a synergistic effect on alveolar stability.
\end{abstract}

Aim of the study: To identify the factors associated with INSURE strategy failure in preterm infants with gestational age $(\mathrm{GA}) \leq 32$ weeks.

Materials and Methods: This was a retrospective cohort study, based on data collected in the Romanian National Registry for RDS patients by three regional (level III) centers between 01.01.2010 and 31.12.2011. All preterm infants of $\leq 32$ weeks GA were included. Prenatal and neonatal information were compared between (Group 1), the preterm infants successfully treated using INtubation-SURfactant-Extubation on nasal CPAP (INSURE) strategy and (Group 2 ), those who needed mechanical ventilation within seventy two hours after INSURE.

Results: A total of 637 preterm infants with GA $\leq 32$ weeks were included in the study. INSURE strategy was performed in fifty seven cases (8.9\%) [ Group 1] and was successful in thirty one patients (54.4\%). No differences were found as regards the studied prenatal and intranatal characteristics between (Group 1) and Group 2 who needed mechanical ventilation. Group 2 preterm infants who needed mechanical ventilation within 72 hours after INSURE had significantly lower mean Apgar scores at 1 and 5 minutes and lower peripheral oxygen saturation (SpO2) during resuscitation at birth $(p<0.05)$. Successful INSURE strategy was associated with greater GA, birth weight (BW), fraction of inspired oxygen (FiO2) during resuscitation, and an increased mean dose of surfactant but these associations were not statistically significant $(p>0.5)$.

Conclusion: In preterm infants $\leq 32$ weeks gestation, increased INSURE failure rates are associated with complicated pregnancies, significantly lower Apgar scores at 1 and 5 minutes, and lower peripheral oxygen saturation during resuscitation.

Keywords: neonatal respiratory distress syndrome, premature infant, INSURE strategy, registries

Received: Received: 03 February 2016 / Accepted: 30 March 2016

\footnotetext{
Correspondence to: Maria Livia Ognean:Bd. Coposu 2-4, Sibiu, Romania, phone: 0040754276584, fax: 0040269215434. E-mail: livia_sibiu@yahoo.com

Silvia Maria Stoicescu: Gh. Polizu Street no. 38-52, Sector 1, Bucuresti, Romania, phone: 0040213168912, fax: 004021 3168963. E-mail: stoicescusilvia@yahoo.com

Oana Boantă: Bd. Coposu 2-4, Sibiu, Romania, phone: 0040269215050, fax: 0040269215434. E-mail: oana_boanta@yahoo.com

Leonard Năstase: Gh. Polizu Street no. 38-52, Sector 1, Bucuresti, Romania, phone: 0040213168912, fax: 004021 3168963. E-mail: nastaseleonard@gmail.com

Carmen Gliga: Gh. Marinescu no. 50 Street, Tg. Mures, Romania, phone: 0040265212 111; fax 0265215 768. E-mail: carmenmov@gmail.com

Manuela Cucerea: Gh. Marinescu no. 50 Street, Tg. Mures, Romania, phone: 0040265 212 111; fax 0265215 768. E-mail: manuelacucerea@yahoo.com
} 


\section{INTRODUCTION}

Respiratory distress syndrome (RDS) is the leading cause of morbidity and death in preterm infants. The incidence of RDS increases with decreasing gestational age (GA) and birth weight (BW) [1], occurring in over $50 \%$ of the preterm infants with $\mathrm{BW}<1.500 \mathrm{~g}$ and in approximately $90 \%$ of those weighing less than $750 \mathrm{~g}$ at birth [2].

Recent important developments in RDS treatment include the use of continuous positive airway pressure (CPAP) [3], antenatal corticosteroid prophylaxis $[4,5]$ and surfactant replacement [6]. These and the improvement in mechanical ventilation (MV) of the neonates in the 1990s, lead to a significant decrease in morbidity and mortality of the preterm infants $[7,8]$.

Increasingly a "new disease", bronchopulmonary dysplasia (BPD) [9], was observed in association with $\mathrm{MV}$, the most severe adverse neonatal outcome of the preterm birth. By the beginning of the 21 century, neonatologists turned their attention towards less invasive respiratory therapies.

Early CPAP is associated with reduced pulmonary morbidity and lower rates of BPD [10]. Currently CPAP is recommended as the first line therapy alternative to intubation and MV for pulmonary stabilization $[6,11]$ even in the delivery room [12-14]. Early surfactant administration has been shown to be more efficient than late treatment [15] and is associated with decreased neonatal mortality, incidence of air leak syndromes, and BPD $[9,16]$. Combining early CPAP with early surfactant administration seemed logical and a study reporting the use of surfactant administration in spontaneously breathing preterm infants [17] was followed by a randomized controlled study [18]. The strategy was named INtubation-SURfactant-Extubation (on nasal CPAP) - INSURE - [19] based on the synergistic effect on functional residual capacity. CPAP was shown to distends alveoli, maintain the patency of the airways during expiration, prevent surfactant depletion and the prevention of alveolar collapse. The INSURE strategy reduces the need and duration of $\mathrm{MV}$, length of oxygen therapy, the need of additional surfactant doses, and length of hospitalization in the neonatal intensive care unit [17-20]. A decreased rate of BPD was reported compared to classical surfactant administration plus MV strategy [16]. However, the reported failure rates vary between $9-50 \%,[11,18-27]$ restricting the universal adaptation of the beneficial effects the strategy.
The aim of this study was to identify the factors associated with INSURE failure in preterm infants with $\mathrm{GA} \leq 32$ weeks.

\section{MATERIAL AND Methods}

The study is a retrospective analysis based on data collected from the Romanian National Registry for RDS by three regional (level III) centers - Institute for Mother and Child Care Polizu București, Regional Neonatal Intensive Care Center Tirgu Mureș, and Neonatology Department of Clinical County Emergency Hospital Sibiu - between 01.01.2010 and 31.12.2011.

The study was approved by the institutional review board and was in accordance with the principles stated in the Declaration of Helsinki.

All preterm infants of $\leq 32$ weeks GA were included in the study.

INSURE strategy was defined as surfactant administration (poractant alpha, Curosurf, Chiesi Pharmaceuticals, Parma, Italy) after intubation, in doses between $100-200 \mathrm{mg} / \mathrm{kg}$, within two hours after birth, followed by manual (bag) or conventional $\mathrm{MV}$, and extubation on nasal CPAP in the following two hours. INSURE failure was defined as the need for MV within seventy two hours after the initiation of INSURE strategy. Infant Flow SiPAP (Viasys Healthcare. Palm Springs, USA) and Bubble CPAP were used to provide nasal CPAP. The use of INSURE strategy or other strategies, nasal CPAP, surfactant administration and MV, or MV alone, was decided by physicians, and based on severity of RDS. Termination of nCPAP was decided by the presence of spontaneous respirations, haemodynamic stability, oxygen saturations of $88-92 \%$, and the fraction of inspired oxygen $\left(\mathrm{FiO}_{2}\right)$ being at least $10 \%$ lower than before surfactant administration. On CPAP, the pressure and $\mathrm{FiO}_{2}$ were adjusted based on clinical signs of RDS, transcutaneous or arterial oxygen tension, and peripheral oxygen saturation $\left(\mathrm{SpO}_{2}\right.$ between $\left.86-93 \%\right)$. Guidelines on $\mathrm{RDS}$ management and oxygen therapy, according to European Guidelines recommendations [13] were revised and implemented in Romania in 2011 [28,29].

Resuscitation and alveolar recruitment was undertaken in the delivery room using Neopuff Infant Resuscitator (Fisher \& Paykel Healthcare Corporation Limited, Auckland, New Zealand). Pulsoximetry was used to measure $\mathrm{FiO}_{2}$.

The Romanian National Registry for RDS collects epidemiological data, information regarding the treat- 
ment and severity of RDS, and the short term outcome in preterm infants with GA $\leq 32$ weeks.

The following information was extracted and analyzed:

- Prenatal - pregnancy complications: maternal diabetes mellitus, preeclampsia, pregnancy hypertension, chorioamnionitis, antenatal corticosteroid administration, preterm rupture of the membranes $>18$ hours, multiple pregnancy, delivery mode, presentation.

- Neonatal characteristics and data: GA, BW, small for gestational age (SGA), gender, Apgar score at 1 and 5 minutes, peripheral oxygen saturation during resuscitation at birth, $\mathrm{FiO}_{2}$ before and one hour after surfactant administration, surfactant dose.

The preterm infants included in the study were divided in 5 groups according to respiratory management:

1. INSURE, CPAP

2. surfactant plus $\mathrm{MV}$

3. $\mathrm{MV}$

4. MV plus CPAP (before or after MV)

5. without RDS (no respiratory support, no surfactant)

In order to analyze the factors associated with INSURE failure the INSURE group was divided in:

\section{A. INSURE success}

B. INSURE failure groups.

Data were reported as values, mean values, standard deviations (SD), and percentages. SPSS 19 was used for data analysis. Independent t-test was used for scale variables while Fisher's exact test or chi square test (where appropriate) were used for the analysis of categorical variables.

The level of significance was set at $\alpha=0.05$. Odds ratio were calculated and confidence intervals (CI) of 95\% were used.

\section{QRESULTS}

A total of 637 preterm infants with mean GA $29.4 \pm 2,2$ weeks (23-32 weeks) and mean BW $1294.3 \pm 383.4 \mathrm{~g}$ (450-2460 g) were included in the study.

RDS was absent in 103 (16.2\%). INSURE strategy was used in 57 cases (8.9\%), mean GA $29.1 \pm 1$,8 weeks (25-32 weeks), mean BW $1205.6 \pm 312.4$ g (570-2250 g), successfully in 31 patients (54.4\%).
Different approaches were seen in the three participating centers (Table 1). CPAP failure was noted with different rates between the centers $(29-100 \%)$; the highest rate of success $(71 \%)$ was achieved by the center with the highest percentage of INSURE use while the highest failure rate was seen in the center where INSURE strategy was used in a lesser extent.

The prenatal data regarding pregnancy complications, maternal diabetes mellitus, preeclampsia, pregnancy hypertension, chorioamnionitis, antenatal corticosteroid administration, preterm rupture of the membranes $>18$ hours, multiple pregnancy, delivery mode, presentation for both study groups are presented in Table 2.

No differences were found between the study groups as regards the studied prenatal and intranatal characteristics. When a composite analysis was performed evaluating the presence of any complication during pregnancy, INSURE failure was associated with an increased frequency of pregnancy complication (Table 2).

The comparison of the neonatal variables, between the INSURE success and INSURE failure groups is presented in Table 3. The only significant differences found between groups were the lower mean Apgar scores at 1 and 5 minutes and lower $\mathrm{SpO}_{2}$ during resuscitation at birth in preterm infants that failed INSURE strategy (Table 2). Preterm infants treated successfully with INSURE strategy had greater $\mathrm{GA}, \mathrm{BW}, \mathrm{FiO}_{2}$ during resuscitation, and received an increased mean dose of surfactant compared to those in the INSURE failure group.

\section{DISCUSSION}

Respiratory distress syndrome, due to lung immaturity and surfactant deficiency, continues to be the chief cause of illness and death in preterm infants $[1,13]$. Respiratory support and surfactant administration are the main therapeutic strategies used in the treatment of $\mathrm{RDS}[7,8]$. A Cochrane review [9] concluded that early surfactant administration decreases both neonatal mortality and pulmonary complications while MV increases the risk for BPD. Studies indicate that early CPAP decreases neonatal mortality and the risk of BPD [10]. It seemed logical that combining early surfactant administration with early CPAP would have a synergistic effect on alveolar stability, preventing alveolar collapse and maintaining the pulmonary functional residual capacity. This effect was demonstrated in ear- 
Table 1. Strategies for RDS management in the centers participating in the study

\begin{tabular}{|c|c|c|c|c|}
\hline Strategy & $\begin{array}{c}\text { Center A } \\
\mathbf{n = 2 4 6}\end{array}$ & $\begin{array}{c}\text { Center B } \\
n=139\end{array}$ & $\begin{array}{c}\text { Center C } \\
\mathbf{n}=\mathbf{2 5 2}\end{array}$ & $\begin{array}{c}\text { All centers } \\
n=637\end{array}$ \\
\hline INSURE, n(\%) & $19(7.7)$ & $31(22.3)$ & $7(2.7)$ & $57(8.9)$ \\
\hline CPAP, $n(\%)$ & $54(22)$ & $73(52.5)$ & $123(47.6)$ & $250(39.2)$ \\
\hline MV1, n(\%) & $26(10.6)$ & $1(0.7)$ & $11(4.3)$ & $38(6)$ \\
\hline Surfactant + MV2, n(\%) & $61(24.8)$ & $13(9.4)$ & $29(11.5)$ & $103(16.2)$ \\
\hline $\mathrm{CPAP}+\mathrm{MV} 3, \mathrm{n}(\%)$ & $15(6.1)$ & $2(1.4)$ & $31(12.3)$ & $48(7.5)$ \\
\hline $\mathrm{MV}+\mathrm{CPAP} 4, \mathrm{n}(\%)$ & $23(9.3)$ & $2(1.4)$ & $8(3.2)$ & $33(5.2)$ \\
\hline Surfactant (late) + CPAP5, n(\%) & - & $3(2.2)$ & - & $3(0.5)$ \\
\hline Surfactant (late) + CPAP + MV6, n(\%) & - & $1(0.7)$ & $1(0.4)$ & $2(0.3)$ \\
\hline Surfactant, $\mathrm{n}(\%)$ & $80(35.5)$ & $48(34.8)$ & $37(14.7)$ & $165(25.9)$ \\
\hline CPAP as first approach, $\mathrm{n}(\%)$ & $88(35.9)$ & $110(79.1)$ & $162(64.3)$ & $360(56.5)$ \\
\hline MV as first approach, $\mathrm{n}(\%)$ & $110(44.6)$ & $16(11.5)$ & $48(19.0)$ & $174(27.3)$ \\
\hline No RDS7, n(\%) & $48(19.5)$ & $13(9.4)$ & $42(16.7)$ & $103(16.2)$ \\
\hline
\end{tabular}

1 Mechanical ventilation; 2 Surfactant administration followed by elective mechanical ventilation; 3CPAP failure followed by mechanical ventilation; 4Elective mechanical ventilation followed by CPAP; 5 Late surfactant administration (more than 2 hours after birth) and successful CPAP; 6Late surfactant administration (more than 2 hours after birth), CPAP failure followed by mechanical ventilation; 7Respiratory distress syndrome

Table 2. Analysis of the prenatal and intranatal characteristics

\begin{tabular}{|c|c|c|c|c|}
\hline & $\begin{array}{c}\text { INSURE success } \\
\mathbf{n}(\%)\end{array}$ & $\begin{array}{l}\text { INSURE failure } \\
n(\%)\end{array}$ & p & OR [Cl 95\%] \\
\hline Complicated pregnancy & $6(19.4)$ & $13(50.0)$ & 0.014 & $4.17[1.28-13.52]$ \\
\hline Diabetes mellitus & 0 & 0 & - & - \\
\hline Eclampsia & $1(3.2)$ & $3(11.5)$ & 0.242 & $3.91[0.38-40.12]$ \\
\hline Arterial hypertension & $3(9.7)$ & $6(23.1)$ & 0.155 & $2.80[0.62-12.55]$ \\
\hline Hemorrhage & 0 & $2(7.7)$ & 0.204 & - \\
\hline Chorioamnionitis & $1(3.2)$ & 0 & 0.544 & - \\
\hline PROM1 > 18 hours & $6(19.4)$ & $4(15.4)$ & 0.486 & $0.76[0.19-3.04]$ \\
\hline Multiple pregnancy (twin) & $8(25.8)$ & $6(23.1)$ & 0.816 & $0.86[0.26-2.91]$ \\
\hline C-section & $13(41.9)$ & $15(57.7)$ & 0.244 & $1.89[0.66-5.43]$ \\
\hline Breech & $9(29)$ & $5(19.2)$ & 0.401 & $0.58[0.17-2.02]$ \\
\hline Antenatal corticosteroids & $16(51.6)^{*}$ & $9(34.6)^{*}$ & 0.204 & $0.49[0.17-1.45]$ \\
\hline No of corticosteroid doses & $1.81 \pm 1.22$ & $1.44 \pm 0.53$ & 0.402 & - \\
\hline
\end{tabular}

Table 3. Analysis of the neonatal characteristics of the study groups

\begin{tabular}{|c|c|c|c|c|}
\hline & $\begin{array}{l}\text { INSURE success } \\
\qquad \mathbf{n}=\mathbf{3 1}\end{array}$ & $\begin{array}{l}\text { INSURE failure } \\
\qquad n=26\end{array}$ & $\mathbf{P}$ & OR [Cl 95\%] \\
\hline BW, mean \pm SD, g & $1233.1 \pm 267.7$ & $1159.4 \pm 351.1$ & 0.373 & - \\
\hline $\mathrm{GA}$, mean $\pm \mathrm{SD}$, weeks & $29.4 \pm 1.7$ & $28.7 \pm 1.8$ & 0.130 & - \\
\hline Apgar score at 1 minute, mean \pm SD & $5.8 \pm 1.8$ & $4.6 \pm 2.3$ & 0.047 & - \\
\hline Apgar score at 5 minutes, mean \pm SD & $7.8 \pm 1.3$ & $6.3 \pm 2.6$ & 0.038 & - \\
\hline FiO2 at resuscitation, mean $\pm \mathrm{SD}, \%$ & $90.0 \pm 22.6$ & $86.3 \pm 29.2$ & 0.618 & - \\
\hline SpO2 at resuscitation, mean \pm SD, $\%$ & $93.1 \pm 4.9$ & $86.0 \pm 14.6$ & 0.045 & - \\
\hline FiO2 before surfactant, mean \pm SD, $\%$ & $68.9 \pm 28.0$ & $70.2 \pm 30.4$ & 0.871 & - \\
\hline FiO2 1 hour after surfactant, mean $\pm \mathrm{SD}, \%$ & $49.48 \pm 22.2$ & $49.2 \pm 22.6$ & 0.958 & - \\
\hline Surfactant dose, mean $\pm \mathrm{SD}, \mathrm{mg} / \mathrm{kg}$ & $172.2 \pm 32.0$ & $158.8 \pm 37.9$ & 0.152 & - \\
\hline Male gender, $\mathrm{n}(\%)$ & $16(51.6)$ & $12(46.2)$ & 0.688 & $0.80[0.28-2.28]$ \\
\hline SGA1, n(\%) & $17(54.8)$ & $12(46.2)$ & 0.522 & $0.71[0.25-2.01]$ \\
\hline
\end{tabular}


lier studies $[17,18]$ and confirmed by a meta-analysis of six trials [9].

Currently, European experts recommend stabilization of the preterm infants in the delivery room using early CPAP, prophylactic surfactant administration in preterm infants less than 26 weeks gestation and those needing intubation for stabilization, early surfactant administration in preterm infants with evidence of RDS and in those without antenatal steroids prophylaxis, early CPAP in preterm infants at risk for RDS until the clinical status is evaluated, INSURE strategy in stable preterm infants receiving early surfactant $[13,14]$.

The Romanian Guideline for RDS treatment was revised in $2011[28,29]$ though implementation of the European recommendations started in some units in 2010. Different implementation rate of the recommendations is demonstrated by the different strategies used in the participating centers (Table 1).

Even though the INSURE strategy can reduce the need for MV and the risk of BPD, different studies report different success rates. The reported failure rates of INSURE strategies vary between $30-50 \%$ [11,19-26] and are mainly due to differences in the population studied and different definition of INSURE failure. However, other factors may influence the results, such as the clinical criteria used to select the patients, different CPAP modes, surfactant types, study design, and even the use of different definitions for INSURE strategy.

The present study tried to identify factors associated with INSURE failure in preterm infants with GA $\leq 32$ weeks. Of the 637 preterm infants with GA $\leq 32$ weeks gestation admitted during the study period, INSURE strategy was applied in 57 cases (8.9\%) with a success rate of $54.4 \%$ (31/57 cases). The lower rate of INSURE strategy use, and success may be due to lack of standardization before national guideline revision including, probably, different criteria for the selection of candidates.

A complicated pregnancy, defined as the presence of any of the following complications: diabetes mellitus, eclampsia, arterial hypertension, chorioamnionitis, PROM > 18 hours, was associated with increased incidence of INSURE failure ( $p=0.014)$ (Table 2). Most of the studies analyzing the risk factors for INSURE failure, evaluated individually these complications and found no association with INSURE failure $[21,25,26]$. The lack of association between INSURE strategy failure and pregnancy complications in these studies may be due to the limited number of included cases.
Brix et al. [21], defined INSURE failure as the need for intubation at seventy two hours after INSURE. He reported that lower GA, lower Apgar score at 5 minutes, $\mathrm{FiO}_{2}>50 \%$ and $\mathrm{paCO}_{2}>53 \mathrm{mmHg}$ two hours before intubation, $\mathrm{pH}<7.3$ and lactate $>2.5 \mathrm{mmol} / 15$ hours before intubation, and the need for inotropic support, are factors predicting the need for MV for more than twenty four hours and suggested that they also predict INSURE failure. Ting et al. [23] found that vaginal birth is associated with lower INSURE failure. In the present study, less preterm infants in the INSURE failure group were delivered vaginally, though no significant difference was observed (Table 2). There was no correlations between INSURE strategy failure related to single or twin pregnancies, reported in the literature, and the present data suggests no association between INSURE strategy failure and twin pregnancy (Table 2). Complete corticosteroid prophylaxis was performed in three patients in both study groups. An analysis was undertaken of antenatal corticosteroid administration and the number of corticosteroid doses administered between the study groups and no significant differences was found ( $p=0.204$ and $p=0.402)$. However fewer patients received prenatal steroids and the mean number of doses was lower in those failing INSURE (Table 2).

Decreased use of prenatal steroids was reported by Ting et al. [23] in association with INSURE failure while Gharehbaghi et al. [26] found no relationship between antenatal corticosteroids and INSURE failure. No relationship was found, in the present study, between presentation at birth and INSURE failure (Table 2).

Significantly lower BW is consistently reported as a risk factor for INSURE failure [19,20,23-26,30]. In the present study, preterm infants in the INSURE failure group had a lower mean BW but the difference was not significant ( $\mathrm{p}>0.05)$ (Table 3). Some studies [21,26,30] reported that lower GA is a risk factor for INSURE failure. Preterm infants failing INSURE in this study had lower mean GA compared to those successfully treated with INSURE but data failed to reach statistical significance ( $\mathrm{p}>0.05)$ (Table 3$)$.

A significantly lower Apgar score at 1 and 5 minutes was associated with INSURE failure in one study [26] $(\mathrm{p}<0.001, \mathrm{p}=0.007)$, and lower Apgar scores $<7$ at 5 minutes were found to be predictive of need for MV for more than 24 hours by Brix et al. [21], while Cherif et al. [25] found no relationship between INSURE failure and Apgar score. 
In the present study, the preterm infants in the INSURE failure group had significantly lower mean Apgar scores at 1 and 5 minutes compared to those in the INSURE success group in our study (Table 3), both mean scores being under seven and suggesting a poor condition at birth and a less satisfactory response to resuscitation. This is also suggested by a significantly lower peripheral oxygen saturation $\left(\mathrm{SpO}_{2}\right)$ in infants failing INSURE strategy $(\mathrm{p}<0.05)$ (Table 3$)$.

Consistent with previous data $[21,25,26]$ no difference was found in the current study as regards gender or association of intrauterine growth restriction and INSURE failure (Table 3).

None of the previous studies reported relationships between $\mathrm{FiO}_{2}$ before or after surfactant administration or surfactant dose with INSURE failure, in agreement with the results of the present study (Table 3 ).

Several differences in study design should be considered. For example, Brix et al. [21] studied prospectively preterm infants with gestational ages $<32$ weeks but defined INSURE failure as re-intubation within seventy two hours after INSURE, and all infants received surfactant in a dose of $200 \mathrm{mg} / \mathrm{kg}$ while Cherif et al [25] administered surfactant (Curosurf) divided in two doses, to the right and left lung, and defined INSURE failure as need for re-intubation within 24 hours if $\mathrm{FiO}_{2}$ $>45 \%$, or $\mathrm{pCO}_{2}>60 \mathrm{mmHg}$, or the infant presented recurrent apnea.

The retrospective observational design of the current study does not allow causal associations to be made. Stratification of the data based on GA and BW may have found relationships with INSURE failure, identifying lower GA or/and BW as risk factors for INSURE failure but this analysis was limited by the number of cases.

\section{CONCLUSIONS}

In preterm infants with gestational ages $\leq 32$ weeks, increased INSURE failure rates are associated with complicated pregnancies, significantly lower Apgar scores at 1 and 5 minutes, and lower peripheral oxygen saturation during resuscitation. A larger study with better inclusion criteria, may identify more clinical variables or even a clinical score that can, rapidly and easily, used to select patients with greater chances for INSURE success, reducing the need for re-intubation and MV with their associated risks, including lung and airway trauma, hypoxic episodes, BPD incidence, and financial costs.

\section{ABbREVIATIONS}

RDS - respiratory distress syndrome; GA - gestational age; BW - birth weight; CPAP - continuous positive airway pressure; nCPAP - nasal continuous positive airway pressure; BPD - bronchopulmonary dysplasia; INSURE - INtubation-SURfactant-Extubation; NICU neonatal intensive care unit; $\mathrm{MV}$ - mechanical ventilation; $\mathrm{FiO}_{2}$ - inspired fraction of oxygen; $\mathrm{SpO}_{2}$ - peripheral oxygen saturation; PROM - premature rupture of amniotic membranes; SGA - small for gestational age; nIPPV - nasal intermittent positive pressure ventilation.

\section{ACKNOWLEDGMENTS}

To Professor Edward Bell, University of Iowa, for reviewing the paper and kind suggestions and support

\section{CONFLICT OF INTEREST}

The authors have no conflicts of interest to disclose.

\section{QREFERENCES}

1. Chard T, Soe A, Costeloe K. The risk of neonatal death and respiratory distress syndrome in relation to birth weight of preterm infants. Am J Perinatol. 1997;14:523-6.

2. Hack M, Horbar JD, Malloy MH, et al. Very low birth weight outcomes of the National Institute of Child Health and Human Development Neonatal Network. Pediatrics 1991;87:587-97.

3. Gregory GA, Kitterman JA, Phibbs RH, Tooley WH, Hamilton WK. Treatment of the idiopathic respiratory-distress syndrome with continuous positive airway pressure. N Engl J Med. 1971;284:1333-40.

4. Roberts D, Dalziel S. Antenatal corticosteroids for accelerating fetal lung maturation for women at risk of preterm birth. Cochrane Database Syst Rev 2006;3:CD004454.

5. Crowley P, Chalmers I, Keirse MJ. The effects of corticosteroid administration before preterm delivery: an overview of the evidence from controlled trials. $\mathrm{Br} J$ Obstet Gynaecol. 1990;97:11-25.

6. Finer NN, Carlo WA, Walsh MC, et al. The Support Group of the Eunice Kennedy Shriver NICHD Neonatal Research Network. Early CPAP versus surfactant in extremely preterm infants. N Engl J Med. 2010;27:1970-9.

7. Ho JJ, Henderson-Smart DJ, Davis PG. Early versus delayed initiation of continuous distending pressure for respiratory distress syndrome in preterm infants. Cochrane Database Syst Rev. 2002:CD002975.

8. Henderson-Smart DJ, Wilkinson A, Raynes-Greenow $\mathrm{CH}$. 
Available online at: www.jccm.ro

Mechanical ventilation for newborn infants with respiratory failure due to pulmonary disease. Cochrane Database Syst Rev. 2002:CD002770.

9. Stevens TP, Harrington EW, Blennow M, Soll RF. Early surfactant administration with brief ventilation vs. selective surfactant and continued mechanical ventilation for preterm infants with or at risk for respiratory distress syndrome. Cochrane Database Syst Rev. 2007;17:CD003063.

10. Kamper J, Wulff K, Larsen C, Lindequist S. Early treatment with nasal continuous positive airway pressure in very lowbirthweight infants. Acta Paediatr. 1993;82:193-7.

11. Ammari A, Suri M, Milisavljevic V, et al. Variables associated with the early failure of nasal CPAP in very low birth weight infants. Journal of Pediatrics 2005;147:341-7.

12. Kattwinkel J, Perlman JM, Aziz K, et al. Part 15: neonatal resuscitation: 2010 American Heart Association Guidelines for Cardiopulmonary Resuscitation and Emergency Cardiovascular Care. Circulation 2010;122:S909-19.

13. Sweet DG, Carnielli V, Greisen G, et al. European Association of Perinatal Medicine: European consensus guidelines on the management of neonatal respiratory distress syndrome in preterm infants- 2010 update. Neonatology 2010;97:402-17.

14. Sweet DG, Carnielli V, Greisen G, et al. European consensus guidelines on the management of neonatal respiratory distress syndrome in preterm infants - 2013 update. Neonatology 2013;103:353-68.

15. Bahadue FL, Soll R. Early versus delayed selective surfactant treatment for neonatal respiratory distress syndrome. Cochrane Database Syst Rev. 2012;11:CD001456.

16. Koch L, Frommhold D, Beedgen B, Ruef P, Poeschl J. Prophylactic Administration of Surfactant in Extremely Premature Infants. Crit Care Res Pract. 2010;2010:235894. doi: 10.1155/2010/235894

17. Victorin LH, Deverajan LV, Curstedt T, Robertson B. Surfactant replacement in spontaneously breathing babies with hyaline membrane disease-a pilot study. Biol Neonate 1990;58:121-6.

18. Verder H, Robertson B, Greisen G, et al. Surfactant therapy and nasal continuous positive airway pressure for newborns with respiratory distress syndrome. Danish-Swedish Multicenter Study Group. N Engl J Med. 1994;331:1051-5.

19. Bohlin K, Gudmundsdottir T, Katz-Salamon M, Jonsson B, Blennow M. Implementation of surfactant treatment during continuous positive airway pressure. J Perinatol.
The Journal of Critical Care Medicine 2016;2(2) • 79

2007;27:422-7.

20. Dani C, Corsini I, Bertini G, et al. The INSURE method in preterm infants of less than 30 weeks' gestation. J Matern Fetal Neonatal Med. 2010;23:1024-9.

21. Brix N, Sellmer A, Jensen MS, Vad Pedersen L, Henriksen TB. Predictors for an unsuccessful INtubationSURfactant-Extubation procedure: a cohort study. BMC Pediatr. 2014;14:155.

22. Nayeri FS, Shirvani TE, Aminnezhad M, et al. Comparison of INSURE Method with Conventional Mechanical Ventilation after Surfactant Administration in Preterm Infants with Respiratory Distress Syndrome: Therapeutic Challenge. Acta Medica Iranica 2014;52:604-8.

23. Ting L, Hong J, Dong-Yun L, Xiang-Hong L. Risk factors for the failure of the InSure method in very preterm infants with respiratory distress syndrome. CJCP 2014;16:610-3.

24. Najafian B, Saburi A, Fakhraei SH, et al. Predicting Factors of INSURE Failure in Low Birth-Weight Neonates with Respiratory Distress Syndrome: A Logistic Regression Model. IJN 2014;5:31-4

25. Cherif A, Hachani C, Khrouf N. Factors associated with INSURE method failure in preterm infants with respiratory distress syndrome. The Internet Journal of Pediatrics and Neonatology 2007;8:1-5.

26. Gharehbaghi MM, Peirovifar A, Ghojazadeh M. Risk factors contributing to the failure of surfactant administration with INSURE method. J Pioneer Med Sci. 2014;4:55-9.

27. Leone F, Trevisanuto D, Cavallin F, Parotto M, Zanardo V. Efficacy of INSURE during nasal CPAP in preterm infants with respiratory distress syndrome. Minerva Pediatr. 2013;65:18792.

28. Stoicescu SM, Năstase L, Ciochină E, et al. Management of respiratory distress syndrome due to surfactant deficit. [Managementul sindromului de detresă respiratorie prin deficit de surfactant]. Ghiduri Clinice pentru Neonatologie. Ghidul 07. Editura Alma Mater Sibiu, Romania.

29. Stoicescu SM, Androne A, Dicu A, et al. Oxygen therapy in neonates [Oxigenoterapia la nou-născut]. Ghiduri Clinice pentru Neonatologie. Ghidul 08. Editura Alma Mater Sibiu, Romania.

30. Kirsten GF, Kirsten CL, Henning PA, et al. The outcome of ELBW infants treated with NCPAP and InSurE in a resource-limited institution. Pediatrics. 2012;129:e952-9. 